\title{
Effect of lithium chloride additive on forward osmosis membranes performance
}

Nawaf Bin Darwish ${ }^{a *}$, Abdullah Alkhudhiri ${ }^{\mathrm{a}}$, Hamad AlRomaih ${ }^{\mathrm{a}}$, Abdulrahman Alalawi ${ }^{\mathrm{a}}$, Mark C Leaper ${ }^{\mathrm{b}}$, Nidal Hilal ${ }^{\mathrm{c}, \mathrm{d}}$

${ }^{a}$ National Centre for Desalination and Water Treatment Technology, King Abdulaziz City for Science and Technology (KACST), Saudi Arabia

${ }^{b}$ Department of Chemical Engineering, Loughborough University, Loughborough, Leicestershire, UK, LE11 3TU.

${ }^{c}$ Centre for Water Advanced Technologies and Environmental Research (CWATER), College of Engineering, Swansea University, United Kingdom

${ }^{\mathrm{d}}$ NYUAD Water Research Centre, New York University Abu Dhabi, Abu Dhabi, United Arab Emirates

*Corresponding author, email: nbindarwish@kacst.edu.sa

\begin{abstract}
The research efforts on the development of ideal forward osmosis membranes with high water flux and low reverse salt flux have been devoted in the recent years. In this study, thin film composite polyamide forward osmosis membranes were prepared. The porous polysulfone (PSU), polyphenylsulfone (PPSU), and polyethersulfone (PESU) substrates used in this study were prepared by the phase inversion process, and the active rejection layer was prepared by interfacial polymerization. All the membranes showed highly asymmetric porous structures with a top dense upper layers and finger-like porous substrates with macro voids in the bottom layer. The addition of $3 \%$ lithium chloride $(\mathrm{LiCl})$ to the membrane substrates resulted in an increase in both the water flux and reverse salt flux. PSU and PESU showed the highest water flux when the active layer faced the feed solution (AL-FS), while the largest water flux was obtained when the active layer faced the draw solution (AL-DS). For all the membranes, the water flux under the AL-DS orientation was higher than that under the AL-FS orientation.
\end{abstract}

Keywords: additives; thin film composite; interfacial polymerization; phase inversion; reverse salt flux. 


\section{Introduction}

Owing to its low energy requirement, low operational cost, and membrane fouling propensity forward osmosis (FO) is considered as a promising sustainable, innovative, and affordable alternative to conventional desalination processes [1]. FO is an osmotic process where the osmotic pressure gradient acts as a driving force for the transportation of water through a semipermeable membrane from the feed solution (low concentration) to the draw solution (high concentration) [2]. The ideal FO Membrane should possess an active layer with a high water flux and low reverse salt flux and a support layer with a high porosity and small thickness (smaller structural parameter $\mathrm{S}$ ) to control internal concentration polarization (ICP) [3]. In addition, FO membranes should be hydrophilic to minimize fouling and should possess good mechanical strength and chemical stability [4]. Depending upon the application, the active rejection layer can be either a reverse osmosis-like skin, which completely rejects ions or a nanofiltration-like skin, which can reject multivalent ions [5]. Various efforts have been made for the development of forward osmosis membranes either a flat sheet or a hollow fibre configuration with high water flux, high salts rejection and low reverse salt flux [6,7]. Fabrication of double-skinned forward osmosis membranes may reduce internal concentration polarization (ICP) but the second skin layer in may persuade additional water transport resistance and decrease water flux [6].

Owing to their high thermal and chemical stabilities, mechanical properties, wide $\mathrm{pH}$ tolerance [8], and superior film forming capability [9] polysulfones have been widely used as membrane materials in membrane fabrication, especially for FO membranes [9]. The chemical structures of PSU, PESU, and PPSU are shown in Fig. 1 [10].

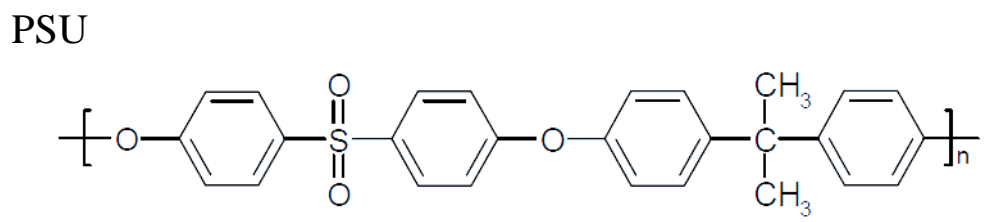

PESU 

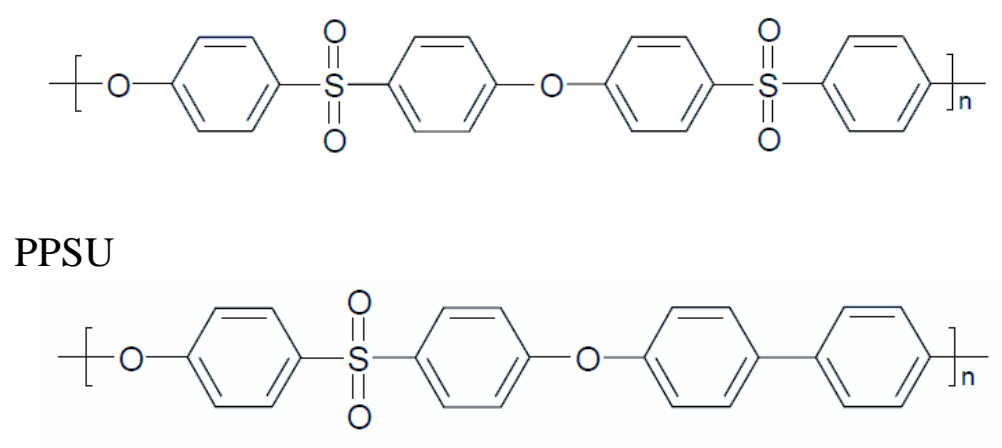

Fig.1 Chemical structures of sulfone polymers

The properties and structure of membranes prepared by the phase inversion technique are affected by various factors. Additives significantly affect the membrane structure. The use of additives in such membranes can improve their morphology and properties. Additives can enlarge or prevent the formation of macrovoids in these membranes, which accelerates the pore formation process and improves the interconnectivity between the pores, thus rendering the membranes hydrophilic [11]. The commonly used additives (either single or mixture) employed in membrane fabrication can be classified into: high-molecular weight polymers such as polyethylene glycols and polyvinylpyrrolidone, organic compounds such as glycerol, alcohols, and inorganic salts such as $\mathrm{LiCl}$ and $\mathrm{ZnCl}_{2}$ [12]. $\mathrm{LiCl}$ is commonly used in membrane fabrication which as a pore-forming additive [13]. The concentration of $\mathrm{LiCl}$ in the dope solution has an effect on the morphology and properties of the fabricated membranes. At low $\mathrm{LiCl}$ concentrations, highly porous membranes with large pore size are obtained because of the increased phase separation rate. On the other hand, high $\mathrm{LiCl}$ concentrations yield membranes with a sponge-like structure because of the increased solution viscosity [14]. Mansourizadeh and Ismail [15] have reported that high concentrations of $\mathrm{LiCl}(7.5 \%)$ in the PVDF solution result in the formation of macrovoids, while low $\mathrm{LiCl}$ concentrations (2.5\%) enhance the permeate flux. Shi et al [16] used lithium chloride ( $\mathrm{LiCl})$ and glycerol as additives for the fabrication of (PVDF-HFP) asymmetric microporous hollow fiber membranes. The addition of these additives improved pure water permeability and altered the morphology and structure of the resultant membranes. In case of fabricating forward osmosis membranes incorporating with different additives. A novel 
TFN FO membrane consisting of a PEI nanofibrous substrate with functionalized multiwalled carbon was fabricated [17]. The results showed an increase in porosity by $18 \%$ and reduction in membrane's structural parameter by $30 \%$. A thin film nanocomposite (TFN) membranes were prepared by incorporating different loadings of titanium dioxide $\left(\mathrm{TiO}_{2}\right)$ nanoparticles into the polysulfone (PSf) substrate [18].

For performance evaluation of forward osmosis process, different polysulfones membranes were fabricated. The influence of the substrate polymers and lithium chloride on FO performance through water flux and reverse salt flux were investigated. Thin film composite (TFC) polyamide FO membranes were fabricated and their morphologies and properties were studied. Polysulfone (PSU), polyphenylsulfone (PPSU), and polyethersulfone (PESU) were used as the substrate polymers.

\section{Materials and methods}

\subsection{Chemicals and membrane materials}

All the chemicals used in this study were of analytical grade and were used as received without any purification.

PSU (PSU3500, molecular weight 75000-81000), PPSU (PPSU5000, molecular weight 52000-55000), and PESU (PESU3000, molecular weight 62000-64000) used to prepare membrane substrates were purchased from Solvay Advanced Polymers (USA). $N$-methyl2-pyrrolidone (NMP, Alfa Aesar, Germany) was used as the solvent for preparing the casting solution. Polyvinylpyrrolidone (PVP, average molecular weight 50000 Da, Acros Organics, China) and lithium chloride ( $\mathrm{LiCl}$, Sigma-Aldrich) were used as the additives in the casting solution.

Chemicals used for the active rejection layer preparation were, Trimesoyl chloride (TMC, Alfa Aesar, Germany), m-phenylenediamine (MPD, Sigma-Aldrich Pvt. Ltd, Singapore), and n-hexane (Alfa Aesar, Germany). 


\subsection{Methodology}

\subsubsection{Experimental setup and membrane performance}

The FO experimental setup unit used in this study is shown in Fig. 2. The draw and feed solutions tanks (with a volume of $1 \mathrm{~L}$ ) were placed on precision scales (Mettler-Toledo, LLC, USA). Feed and draw solutions were circulated using peristaltic pumps (WT3000, Longer pump, China). In-line conductivity sensors (Mettler-Toledo, LLC, USA) were used to measure and record the conductivities of both the feed and draw solutions. All the conductivity sensors and precision scales were connected to a computer data logging system to record the conductivity and weight changes in both tanks on the time scale of 5 min. All the experiments were carried out for $4 \mathrm{~h}$. A $0.6 \mathrm{M} \mathrm{(35000} \mathrm{ppm)} \mathrm{sodium} \mathrm{chloride}$ solution was used as a draw solution to mimic the level of total dissolved solids (TDS) in seawater and distilled water was used as the feed solutions.

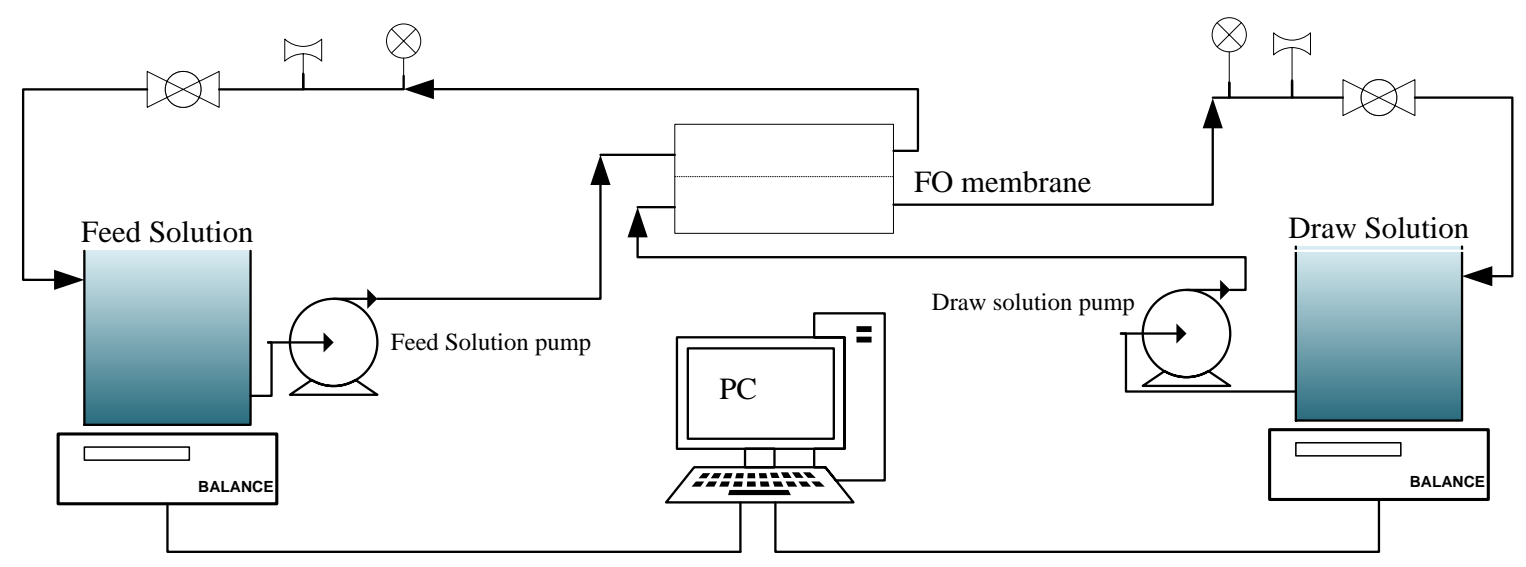

Fig. 2 FO experimental setup unit

The FO water flux $\left(J_{v}\right)$ of the membranes was calculated by measuring the change in their feed solution weights as follows:

$$
\mathrm{J}_{\mathrm{V}}=\frac{\Delta \mathrm{V}_{\text {feed }}}{\mathrm{A}_{\mathrm{m}} \cdot \Delta \mathrm{t}}
$$

Where, $\Delta V_{\text {feed }}(\mathrm{L})$ represents the change in the feed solution volume over a fixed time $\Delta t$ (h) and $\mathrm{A}_{\mathrm{m}}\left(\mathrm{m}^{2}\right)$ is the $\mathrm{FO}$ membrane effective surface area. 
The reverse salt flux $\left(\mathrm{J}_{\mathrm{S}}\right)$ was calculated using the concentration increase in the feed solution as follows $[19,20]$ :

$$
J_{S}=\frac{C_{t} V_{t}-C_{0} V_{0}}{A \Delta t}
$$

where $\mathrm{C}_{0}$ and $\mathrm{C}_{\mathrm{t}}(\mathrm{g} / \mathrm{L})$ are the feed initial concentration and concentration at time $\mathrm{t}$, respectively and $V_{0}(L)$ and $V_{t}(L)$ are the initial feed solution volume and feed solution volume at time t, respectively.

The water permeability (A) was calculated according to the following equation:

$$
A=\frac{J}{\Delta P}
$$

where $\Delta P$ is the applied trans-membrane pressure and $J$ is the permeate water flux.

Salt rejection $(R)$ was determined by measuring the conductivities of the feed and permeate using Model $3540 \mathrm{pH} /$ conductivity meter (Jenway, UK) and applying the following equation:

$$
R=1-\frac{C_{p}}{C_{f}} \times 100
$$

where $C_{f}$ and $C_{p}$ are the feed and permeate salt concentrations, respectively.

The salt permeability (B) was calculated according to the following equation:

$$
\mathrm{B}=\left(\frac{1}{R}-1\right) \cdot \mathrm{J}
$$

The porosity of the membranes $(\varepsilon)$ was determined by applying Gravimetric measurements using the following equation [21]:

$$
\varepsilon=\frac{\left(m_{w e t}-m_{d r y}\right) / \rho_{w}}{\left(m_{w e t}-m_{d r y}\right) / \rho_{w}+{ }^{\left(m_{d r y}\right) / \rho_{p}}} \times 100
$$

where $m_{d r y}$ and $m_{w e t}$ are the dry and wet masses of the membranes, respectively, and $\rho_{w}$ and $\rho_{p}$ are the water and polymer densities, respectively.

The structural parameter (S) value can be evaluated using the following equations for ALFS and AL-DS, respectively [22]: 
AL-FS

$$
S=\frac{D}{J_{v}}\left[\ln \frac{A \pi_{\text {draw }}+B}{A \pi_{\text {feed }}+B+J_{v}}\right]
$$

AL-DS

$$
S=\frac{D}{J_{v}}\left[\ln \frac{A \pi_{d r a w}+B-J_{v}}{A \pi_{\text {feed }}+B}\right]
$$

where $\mathrm{D}$ is the solute diffusion coefficient; $\pi_{\text {draw }}$ and $\pi_{\text {feed }}$ are the draw and feed solutions osmotic pressures respectively.

\subsubsection{Characterizations of membranes}

The observation of membranes samples morphologies was carried out using a JEOL JSM7100F scanning electron microscope (SEM). Prior to the test, a SPI-module sputter coater was used to cover the dried membrane samples with a thin layer of gold.

The contact angle (CA) measurements of membranes were carried out using OCA 35 Optical Contact Angle Meter (DataPhysics, Germany) via the standard sessile drop technique. The membranes were kept in air for $24 \mathrm{~h}$ before the measurements to dry. The CA was measured thrice and the average value was calculated of each sample.

\subsubsection{Preparation of TFC FO membranes}

Six TFC FO membranes were fabricated in the current work and their preparation parameters are listed in Table 1.

Table 1 TFC FO membranes synthesis parameters

\begin{tabular}{cccccc}
\hline Sample & Polymer & Polymer $(w t \%)$ & LiCl (wt \%) & PVP (wt \%) & NMP (wt \%) \\
\hline PSU-0 & PSU 3500 & 17.5 & 0 & 0.5 & 82.0 \\
\hline PSU-3 & PSU 3500 & 15.5 & 3.0 & 0.5 & 81.0 \\
\hline PESU-0 & PESU 3000 & 17.5 & 0 & 0.5 & 82.0 \\
\hline PESU-3 & PESU 3000 & 15.5 & 3.0 & 0.5 & 81.0 \\
\hline PPSU-0 & PPSU 5000 & 17.5 & 0 & 0.5 & 82.0 \\
\hline PPSU-3 & PPSU 5000 & 15.5 & 3.0 & 0.5 & 81.0 \\
\hline
\end{tabular}




\subsubsection{Preparation of FO substrate}

The phase inversion process was used to fabricate all the TFC FO membrane substrates. In order to prepare the casting solution for FO substrates, PSU, PESU, PPSU, PVP, and LiCl (Table 1) were dissolved in NMP and stirred at $70{ }^{\circ} \mathrm{C}$ until a homogeneous solution was formed which then cooled down to room temperature. The dope solutions were degassed in an air-tight bottle for $24 \mathrm{~h}$. The dope solutions were then casted onto a clean glass plate to form a uniform film with a thickness of $150 \mu \mathrm{m}$ using an Elcometer 4340 motorised film applicator with a traverse speed of $70 \mathrm{~mm} / \mathrm{sec}$. The film formed on the glass plate was immersed into a tap water coagulation bath at $25^{\circ} \mathrm{C}$. The water in the coagulant bath was changed 3-4 times to remove the excess solvent. Prior to interfacial polymerization, the substrates were stored in ultrapure water.

\subsubsection{Synthesis of the active rejection layer}

The active rejection layer was prepared by interfacial polymerization on the surface of the PSU, PESU, and PPSU substrates prepared in the previous section. First, the substrates were heated in ultrapure water at $70^{\circ} \mathrm{C}$ for $5 \mathrm{~min}$ and then cooled down to room temperature followed by immersion in an aqueous solution of MPD (1 wt.\%) for $3 \mathrm{~min}$ and then dried in air for 1 hour to remove the excess MPD. The polyamide rejection layer is formed by pouring a TMC $(0.05 \% \mathrm{wt}$.)/n-hexane solution for $1 \mathrm{~min}$ onto the substrate surfaces which

react with the MPD to form the layer. The residual monomers were removed by rinsing the TFC composite membranes in tap water and then stored in boxes filled with deionized (DI) water (prior to evaluation).

\section{Results and Discussion}

\subsection{Membrane substrates characterization}

A 0.6 M (35000 ppm) sodium chloride solution was used as a draw solution with an osmotic pressure of approximately 27.75 bar. Distilled water was used as the feed solutions. 
To investigate the influence of $\mathrm{LiCl}$ on the structure of the $\mathrm{FO}$ membranes, different flatsheet substrates were fabricated with and without $\mathrm{LiCl}$. The water permeability of the fabricated membranes in the current work along with those reported elsewhere (CTA-W and CTA-NW [23], TFC control, $\mathrm{TFC}_{\mathrm{TiO} 2}, \mathrm{TFC}_{\mathrm{TiO} / \mathrm{GO}}$ and $\mathrm{TFC}_{\mathrm{GO}}$ [24] and HTI-NW (commercial) and HTI-ES (commercial) [25] ) are summarized in table 2.

The water permeability A of a membrane were evaluated by RO tests over an applied pressure range of 1-5 bar with ultrapure water as feed while the salt permeability was evaluated at pressure 5 bar and $1 \mathrm{~g} \mathrm{NaCl} / \mathrm{L}$. The feed and permeate concentration were calculated by measuring their conductivities using Model $3540 \mathrm{pH} /$ conductivity meter (Jenway, UK).

It is clear from table 2; the water permeability was significantly improved with the addition of lithium chloride. From table 3, the results of contact angle measurements show that the existence of $\mathrm{LiCl}$ in the casting solution decreased the contact angle of the fabricated membranes, which indicates the improvement of the hydrophilicity of the membranes. This observation can be attributed to the hydrophilicity of $\mathrm{LiCl}$. When $\mathrm{LiCl}$ particles added to the dope solution, they move towards the surface of the membranes, which cause the increase in the hydrophilicity of membranes. The improvement in the hydrophilicity with the increased porosity of the fabricated membranes had made the water permeability increased of PSU, PESU and PPSU by 20.85, 21.57 and 21.95\% respectively. 
Table 2 Water permeability of the membranes

\begin{tabular}{|c|c|c|c|c|c|}
\hline Sample & $\begin{array}{c}\text { Water permeability } \\
\text { A }\left(\mathbf{L} / \mathbf{m}^{2} . h . b a r\right)\end{array}$ & $\begin{array}{c}\mathrm{NaCl} \\
\text { rejection \% }\end{array}$ & $\begin{array}{c}\text { Salt } \\
\text { permeability B } \\
\left(10^{-8} \mathbf{m} / \mathbf{s}\right)\end{array}$ & B/A (kPa) & Ref. \\
\hline PSU-0 & 0.446 & 94.3 & 1.23 & 9.93 & This work \\
\hline PSU-3 & 0.539 & 95.3 & 1.43 & 9.55 & This work \\
\hline PESU-0 & 0.394 & 94.2 & 1.03 & 9.41 & This work \\
\hline PESU-3 & 0.479 & 94.8 & 1.11 & 8.34 & This work \\
\hline PPSU-0 & 0.378 & 94.3 & 1.45 & 13.81 & This work \\
\hline PPSU-3 & 0.461 & 97.6 & 1.52 & 11.87 & This work \\
\hline CTA-W & 0.33 & 81.9 & $4.0+-0.9$ & 47 & [23] \\
\hline CTA-NW & 0.46 & 92.4 & $2.7+-0.2$ & 22 & [23] \\
\hline $\mathrm{TFC}_{\text {control }}$ & 0.40 & 96 & $0.42 \pm 0.15$ & 3.75 & [24] \\
\hline $\mathrm{TFC}_{\mathrm{TiO} 2}$ & 0.55 & 94.4 & $0.84 \pm 0.07$ & 5.42 & [24] \\
\hline $\mathrm{TFC}_{\mathrm{TiO} 2 / \mathrm{GO}}$ & 0.58 & 91.1 & $1.44 \pm 0.34$ & 8.94 & [24] \\
\hline $\mathrm{TFC}_{\mathrm{GO}}$ & 0.61 & 90.1 & $1.89 \pm 0.07$ & 11.18 & [24] \\
\hline $\begin{array}{l}\text { HTI-NW } \\
\text { (commercial) }\end{array}$ & 0.48 & 90 & 2.7 & 20.14 & [25] \\
\hline $\begin{array}{c}\text { HTI-ES } \\
\text { (commercial) }\end{array}$ & 0.54 & 92 & 3.42 & 22.50 & [25] \\
\hline
\end{tabular}


Table 3 FO membrane substrates Characteristics

\begin{tabular}{ccccc} 
Sample & Thickness $(\boldsymbol{\mu m})$ & Porosity $\%$ & S value $(\mathbf{m m})$ & CA \\
PSU-0 & 150 & 80.48 & $0.50 \pm 0.08$ & 77 \\
PSU-3 & 150 & 83.78 & $0.19 \pm 0.17$ & 63.7 \\
\hline PESU-0 & 150 & 81.42 & $0.70 \pm 0.14$ & 76.6 \\
\hline PESU-3 & 150 & 87.41 & $0.19 \pm 0.08$ & 63.8 \\
\hline PPSU-0 & 150 & 82.52 & $0.62 \pm 0.07$ & 78.6 \\
\hline PPSU-3 & 150 & 88.80 & $0.24 \pm 0.06$ & 66.5
\end{tabular}

\subsection{Morphology of the FO membranes}

The SEM images of the top and bottom surfaces of the PSU, PESU, and PPSU membranes are shown in Figs. 3 and 4. Figure 3 shows that the membranes had have smooth uniform layers contained much smaller pore size. This could be due to the formation of a skin layer that was induced by phase inversion process.

(1)

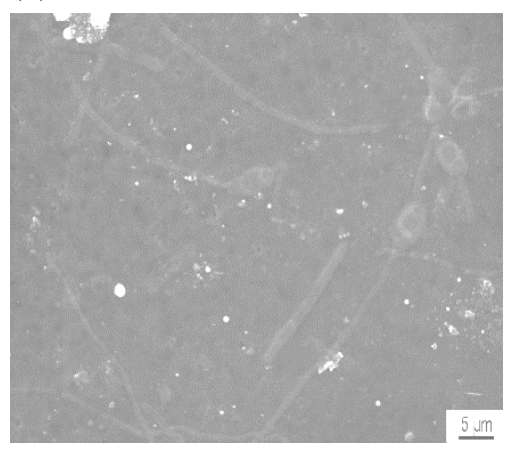

(4)
(2)

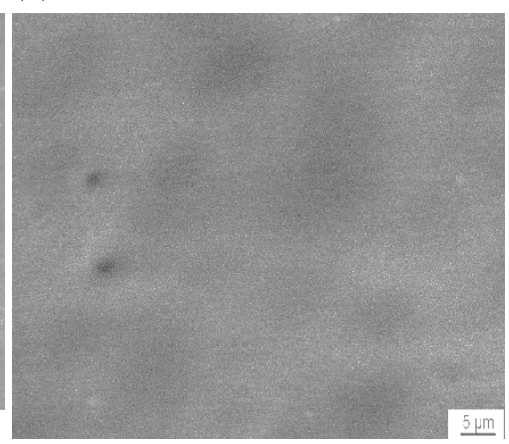

(5)
(3)

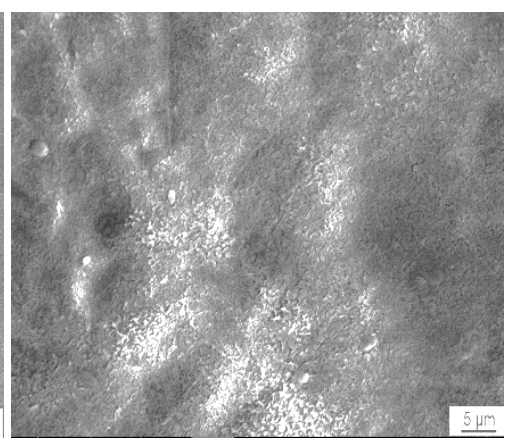

(6) 

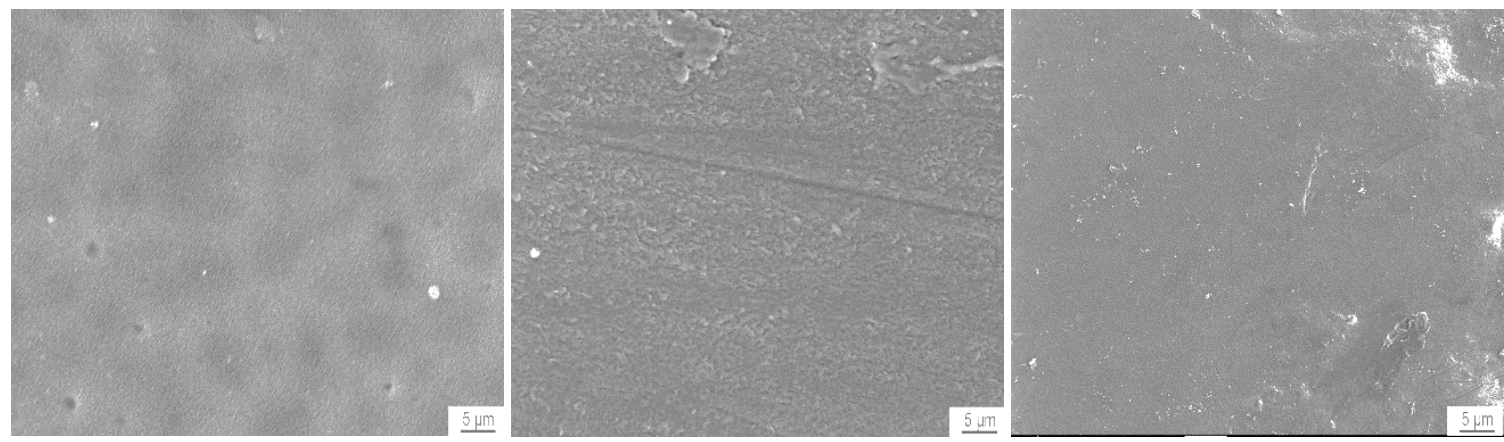

Fig. 3 SEM images of the top surfaces of (1) PSU-0, (2) PSU-3, (3) PESU-0, (4) PESU-3, (5) PPSU-0, and (6) PPSU-3

The bottom surfaces of the membranes are shown in Fig. 4. All the substrates showed sub-micrometre pores. In addition, the porosity increase with the presence of lithium chloride as discussed earlier in table 2.

(1)

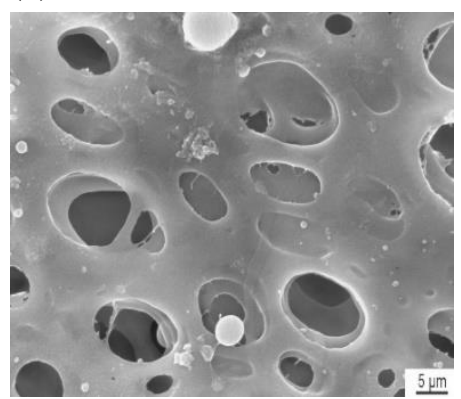

(4)

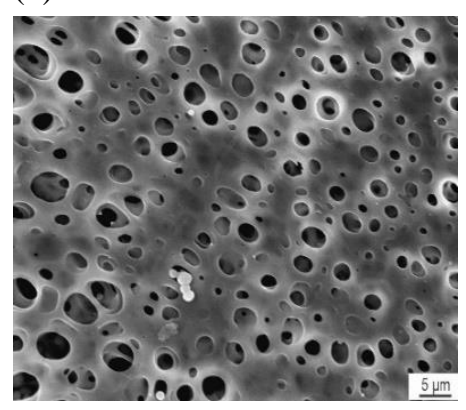

(2)

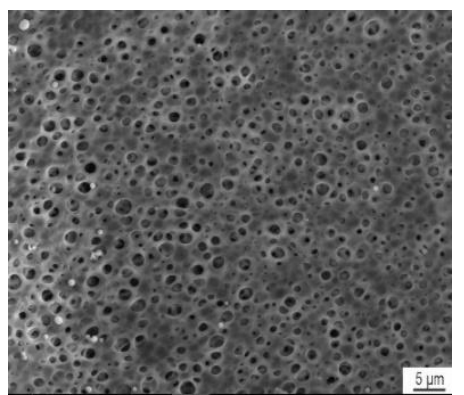

(5)

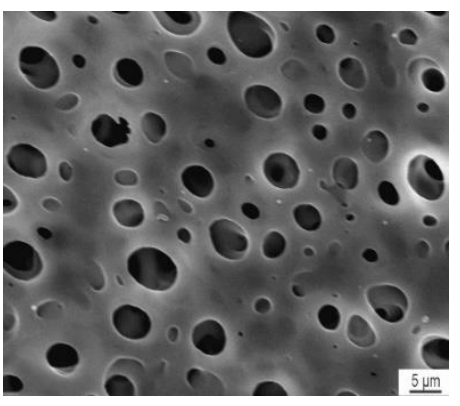

(3)

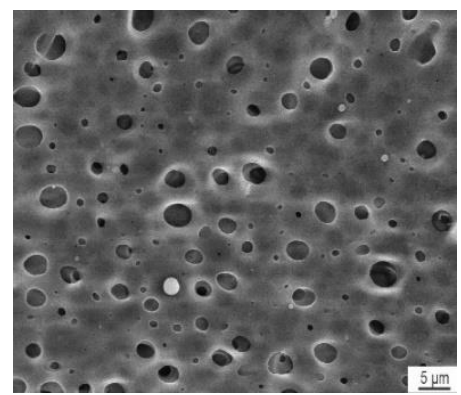

(6)

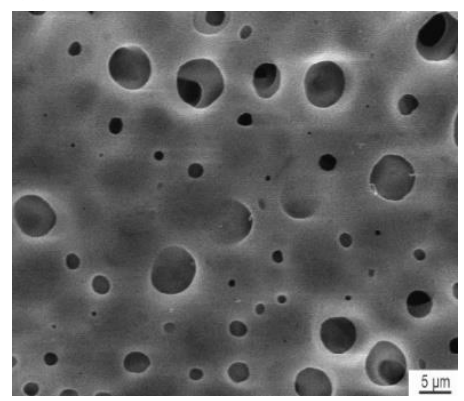

Fig. 4 SEM images of the bottom surfaces of (1) PSU-0, (2) PSU-3, (3) PESU-0, (4) PESU3, (5) PPSU-0, and (6) PPSU-3 
(1)

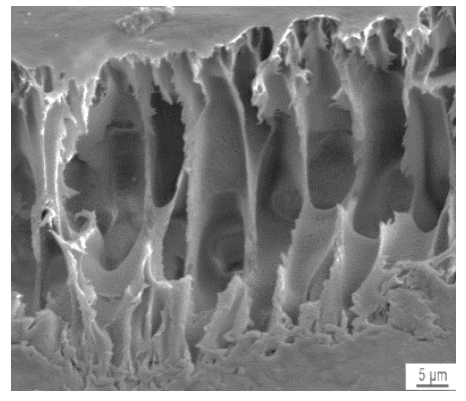

(4)

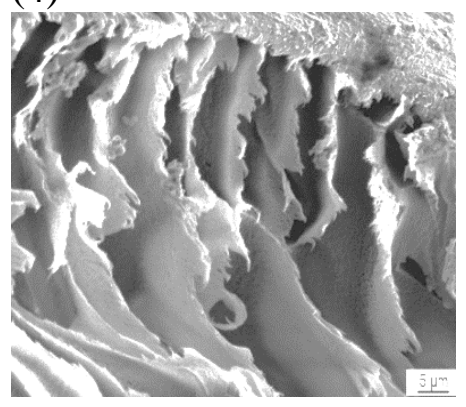

(2)

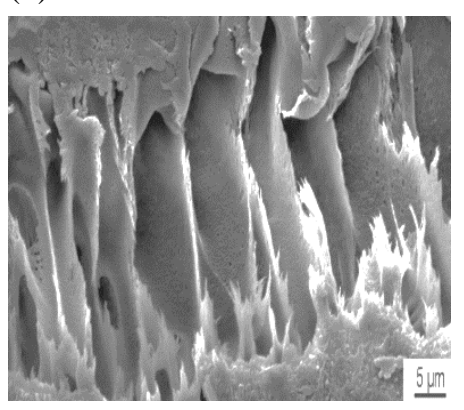

(5)

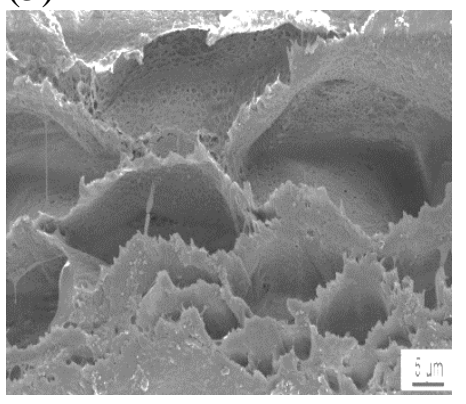

(3)

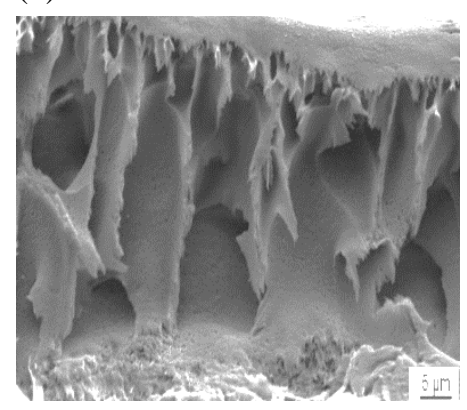

(6)

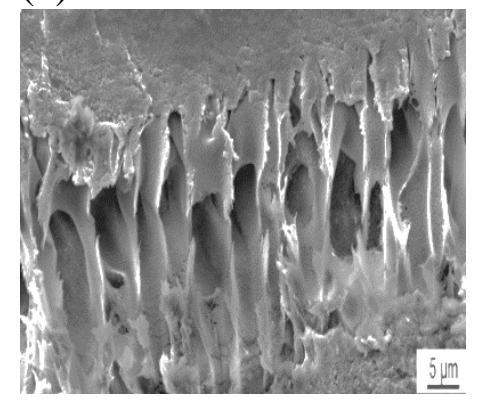

Fig. 5 SEM images of the cross-section of (1) PSU-0, (2) PSU-3, (3) PESU-0, (4) PESU3, (5) PPSU-0, and (6) PPSU-3

The membrane performance can be affected by the morphology of internal pores structure. The impact of $\mathrm{LiCl}$ additive on the internal pores structure was evaluated by analysis of cross-sectional SEM images. It is reported that the structure of asymmetric polymer membranes is significantly affected by the solvent and additive used in their preparation [26]. The cross-sectional SEM images for all cast membranes are presented in Figure 5. Membranes without presence of $\mathrm{LiCl}$ show separate closed finger-like porous sublayers with macro voids in the bottom layer. With the addition of $\mathrm{LiCl}$, the main characteristics of a highly asymmetric structure appears composing of a dense skin layer on top and a thick porous layer with finger like pores in the bottom . It is believed that the addition of hydrophilic nanoparticles to the casting solution will facilitate faster water molecules transfer from water coagulation bath to substrate, causing in long finger-like structure formation and enhanced the membrane porosity [25]. 


\subsection{FO performance of the membranes}

A bench scale forward osmosis setup shown in Fig. 2 was used for the evaluation of TFC membranes performance. Both draw and feed solutions were kept circulated for $4 \mathrm{hrs}$ at a flow rate $400 \mathrm{ml} / \mathrm{min}$. water flux and reverse salt flux were measured and used to evaluate the performance of the membranes under both AL-FS and AL-DS orientations.

\subsubsection{Water flux}

The water flux values of the synthesized membranes obtained for the AL-FS and AL-DS orientations are shown in Figs. 6(a) and 6(b), respectively. From these figures, it can be observed that the addition of $\mathrm{LiCl}$ to the membrane substrates resulted in an increase in the water flux because of the improvement in their pore structure (since $\mathrm{LiCl}$ is a commonly used pore former) [14]. Figure 6(a) shows that with the addition of $\mathrm{LiCl}$ (3 wt. \%) the water flux increased from 3.59 to $6.71 \mathrm{~L} /\left(\mathrm{m}^{2} \mathrm{~h}\right)(87 \%)$ for PSU, 2.85 to $6.88 \mathrm{~L} /\left(\mathrm{m}^{2} \mathrm{~h}\right)(141 \%)$ for PESU, and 3.04 to $5.72(88.2 \%) \mathrm{L} /\left(\mathrm{m}^{2} \mathrm{~h}\right)$ for PPSU. The same trend was observed in the AL-DS orientation (Fig. 6(b)). Figure 6(b) shows that in the AL-DS orientation, the water flux increased from 5.09 to $7.29 \mathrm{~L} /\left(\mathrm{m}^{2} \mathrm{~h}\right)(43.2 \%)$ for PSU, 3.77 to $10.67 \mathrm{~L} /\left(\mathrm{m}^{2} \mathrm{~h}\right)(183 \%)$ for PESU, and 4.13 to $8.48(105 \%) \mathrm{L} / \mathrm{m}^{2} \mathrm{~h}$ for PPSU. The PESU-3 membrane showed the highest water flux in both the AL-FS $\left(6.88 \mathrm{~L} /\left(\mathrm{m}^{2} \mathrm{~h}\right)\right)$ and AL-DS $\left(10.67 \mathrm{~L} /\left(\mathrm{m}^{2} \mathrm{~h}\right)\right)$ orientations.

The results showed that the water flux in the AL-DS orientation was higher than that in the AL-FS orientation for all membranes. The AL-DS orientation is desirable for low salinity feed solutions $[27,28]$. Since the feed solution used in this study was DI water, the AL-DS orientation showed better water flux than the AL-FS orientation. In the AL-FS orientation, ICP is severe as the draw solute passes through the porous side of the membrane, resulting in a low water flux [27, 29]. Cui et al. [30] and Mi and Elimelech [31] showed that when DI water is used as the feed solution, the AL-DS orientation shows much higher water flux than the AL-FS orientation because the former shows concentrative ICP, while the latter shows dilutive ICP. 
The structural parameter $(\mathrm{S})$ is defined as

$$
S=t \tau / \varepsilon
$$

where $t$ is the support layer thickness, $\tau$ is the tortuosity, and $\varepsilon$ is the porosity. The $S$ value is one of the important intrinsic membrane parameters. Both ICP and water flux ae affected directly by the value of the structural parameter (S). Reducing the structural parameters through reducing tortuosity and enhancing porosity and hydrophilicity of the support membrane are effective way to increase water flux and reduce ICP. It can be clearly seen from table 3, that the structural values (S) of the membranes incorporating lithium chloride additive are low compared to the others without $\mathrm{LiCl}$. This finding means that a thin membrane with low tortuosity and open porous structure is producing with the existence of lithium chloride in the membrane substrate preferable for FO process, which gives a high water flux and substantially reduces ICP. It can be concluded that $\mathrm{LiCl}$ is really a good modifier for the substrate of composite membrane, enhancing the hydrophilicity of membranes and reduce the structural parameter values, leading to minimal ICP and higher water flux.

a.

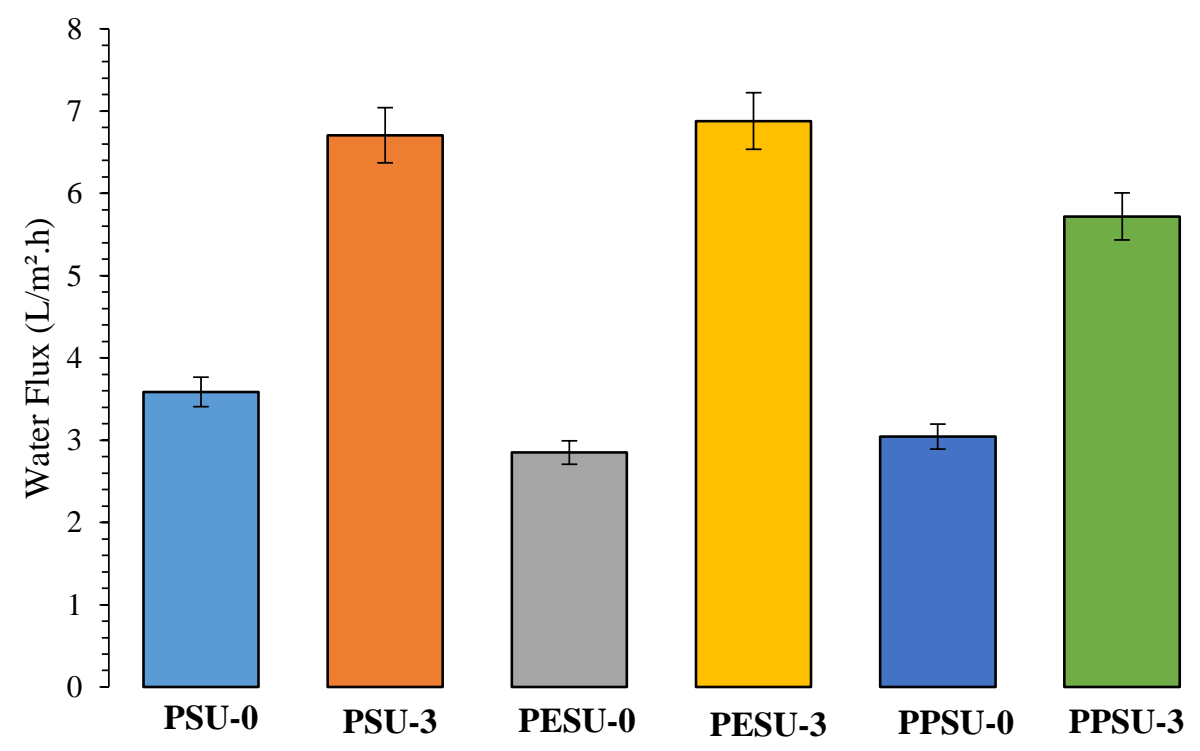

b. 


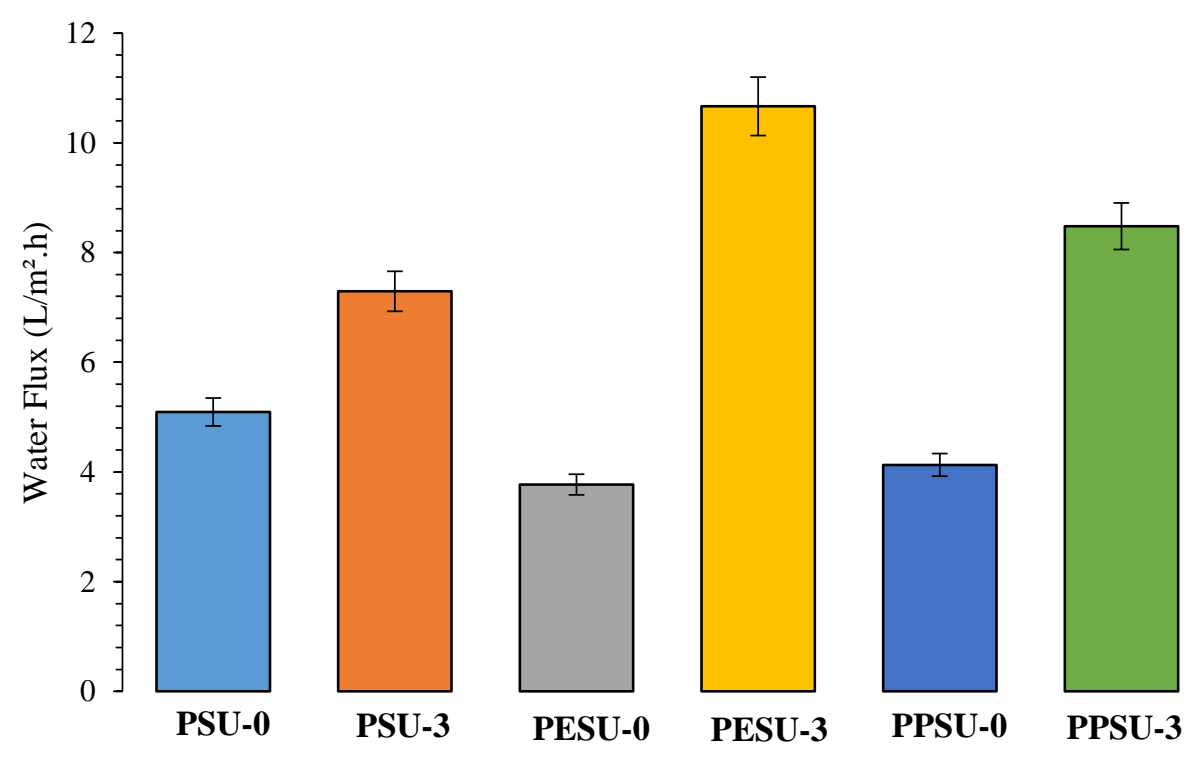

Fig. 6 Water flux of the synthesized membranes. Testing conditions: Feed solution: DI water, Draw Solution: 0.6 M NaCl, membrane orientation: a) AL-FS, b) AL-DS

Figure 7(a) shows the concentrative ICP model, in which the draw solution faced the active layer. The dilutive ICP model is shown in Fig. 7(b), in which the draw solution faced the support layer [32].

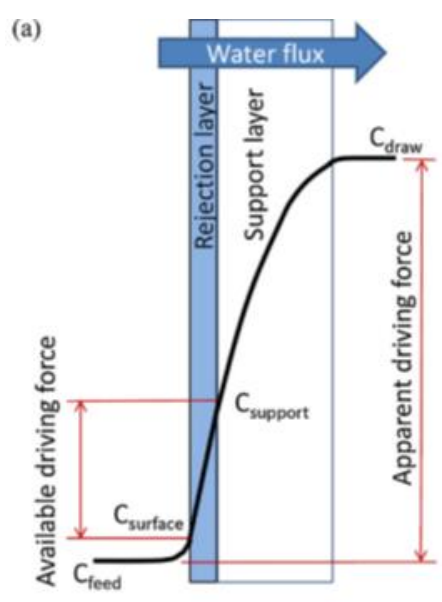

Active layer facing feed water (support layer facing draw solution) (b)

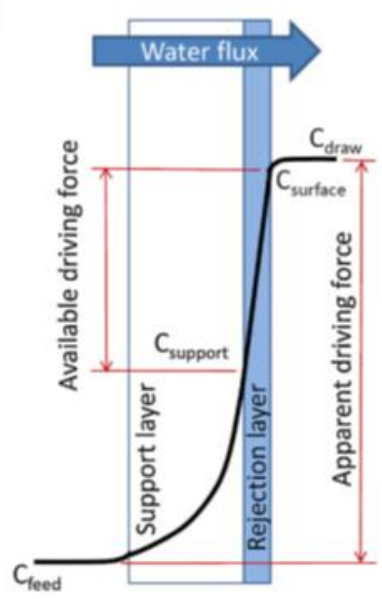

Active layer facing draw solution (support layer facing feed water)

Fig. 7 Internal concentration polarization model. (a) AL-FS (b) AL-DS [32] 


\subsubsection{Reverse and specific reverse salt flux}

Due to the concentration gradient between the draw solution and the feed solution, some of the draw solutes move to the feed solution, which called reverse salt flux. This movement degrades the membrane performance [27, 33]. However, a high reverse salt flux can cause a contamination of the feed solution, and reduce the osmotic pressure difference across the membrane [34]. The reverse salt flux $\left(\mathrm{J}_{\mathrm{s}}\right)$ of the FO membranes was calculated by estimating the change in the $\mathrm{NaCl}$ concentration of the feed solution, which was measured every $5 \mathrm{~min}$ by monitoring the conductivity changes of the feed solution.

The specific reverse salt flux $\left(\mathrm{J}_{\mathrm{s}} / \mathrm{J}_{\mathrm{v}}(\mathrm{g} / \mathrm{L})\right)$ of an FO membrane is defined as the ratio of its reverse salt flux $\left(\mathrm{J}_{\mathrm{S}}\left(\mathrm{g} /\left(\mathrm{m}^{2} \mathrm{~h}\right)\right)\right)$ and water flux $\left(\mathrm{J}_{\mathrm{v}}\left(\mathrm{L} /\left(\mathrm{m}^{2} \mathrm{~h}\right)\right)\right)$ and is used for estimating the quantity of the draw solute lost from the draw solution per litre of the water produced during FO [35, 36]. The specific reverse salt flux of a membrane is measured when DI water is used as the feed solution. The water flux, reverse salt flux, and specific reverse salt flux of all the fabricated membranes for both the AL-FS and AL-DS membrane orientations (Figs. 8(a) and 8(b), respectively) are listed in Table 4.

Table 2 FO water flux, reverse salt flux, and specific reverse flux of the synthesized TFC FO membranes

\begin{tabular}{|c|c|c|c|c|}
\hline Membrane & $\begin{array}{c}\text { Water flux }\left(\mathbf{L} / \mathbf{m}^{2} h\right) \\
(\text { AL-FS/AL-DS) }\end{array}$ & $\begin{array}{l}\text { Reverse salt flux }\left(g / \mathbf{m}^{2} h\right) \\
\text { (AL-FS/AL-DS) }\end{array}$ & $\begin{array}{c}\text { Specific reverse salt flux }(\mathrm{g} / \mathrm{L}) \\
\text { (AL-FS/AL-DS) }\end{array}$ & Ref. \\
\hline PSU-0 & $3.59 / 5.09$ & $5.33 / 6.69$ & $1.49 / 1.31$ & This work \\
\hline PSU-3 & $6.71 / 7.29$ & $6.84 / 8.29$ & $1.02 / 1.14$ & This work \\
\hline PESU-0 & $2.85 / 3.77$ & $4.56 / 6.43$ & $1.60 / 1.71$ & This work \\
\hline PESU-3 & $6.88 / 10.67$ & $6.86 / 8.23$ & $1.00 / 0.77$ & This work \\
\hline PPSU-0 & $3.04 / 4.13$ & $4.95 / 6.67$ & $1.63 / 1.62$ & This work \\
\hline PPSU-3 & $5.72 / 8.48$ & $7.88 / 9.42$ & $1.33 / 1.11$ & This work \\
\hline$T F C_{\text {control }}$ & $5.9 / 13.0$ & $1.8 / 2$ & $0.3 / 0.15$ & [24] \\
\hline $\mathrm{TFC}_{\mathrm{TiO} 2}$ & $12 / 17$ & $2 / 2.3$ & $0.16 / 0.13$ & [24] \\
\hline $\mathrm{TFC}_{\mathrm{TiO} 2 / \mathrm{GO}}$ & $12.3 / 21$ & $2.3 / 3$ & $0.19 / 0.14$ & [24] \\
\hline $\mathrm{TFC}_{\mathrm{GO}}$ & $11 / 12$ & $2.1 / 2.5$ & $0.19 / 0.21$ & [24] \\
\hline $\begin{array}{c}0.5 \mathrm{MWfT} / \mathrm{M}- \\
\mathrm{P}(\mathrm{H}-\mathrm{cell})\end{array}$ & $8.4 / 12$ & $3.5 / 6$ & $0.41 / 0.5$ & [37] \\
\hline
\end{tabular}


The PESU-0 and PPSU-0 membranes showed the lowest reverse salt flux (4.56 and 4.95

$\mathrm{g} / \mathrm{m}^{2} . \mathrm{h}$, respectively) when the active layer faced the feed solution. The PESU-0 and PPSU-0 membranes showed the reverse salt flux values of 6.43 and $6.67 \mathrm{~g} / \mathrm{m}^{2} \mathrm{~h}$, respectively under the AL-DS membrane orientation. Similar to the water flux, the reverse salt flux of the membranes was also affected by the addition of $\mathrm{LiCl}$. It increased with the addition of $\mathrm{LiCl}$ in the casting solution. From Table 4, it can be observed that under the AL-FS orientation, the membranes showed a specific reverse salt flux in the range of $1-1.63 \mathrm{~g} / \mathrm{L}$. On the other hand, under the AL-DS orientation, a specific reverse salt flux of $0.77-1.71 \mathrm{~g} / \mathrm{L}$ was obtained. Low specific reverse salt flux is desirable as it indicates that more water can pass through the membrane and little salt is lost from the draw solution to the feed solution, resulting in a high membrane efficiency. Ideal FO membranes should possess a high-water flux $J_{v}$ and a low reverse salt flux $\left(J_{s}\right)$. A large $J_{s}$ value indicates that a large quantity of the draw solute can leak into the feed solution, which is unfavourable for FO operation and can cause severe ICP as well as membrane fouling [38]. In the AL-DS orientation, the ICP phenomenon is caused by (1) the accumulation of the solutes from the feed water that are retained by the rejection layer and (2) the reverse salt diffusion across the support layer of FO membrane from the DS solution [38]. Salt permeability/water permeability (B/A) ratio is one of the important properties of forward osmosis membranes [18]. The lower value of B/A ratio, the better performance membranes in reducing salt reverse flux during FO process. From table 2, the value of $\mathrm{B} / \mathrm{A}$ ratio is lower for the membranes with $\mathrm{LiCl}$ compared with other membranes without $\mathrm{LiCl}$. 
a.

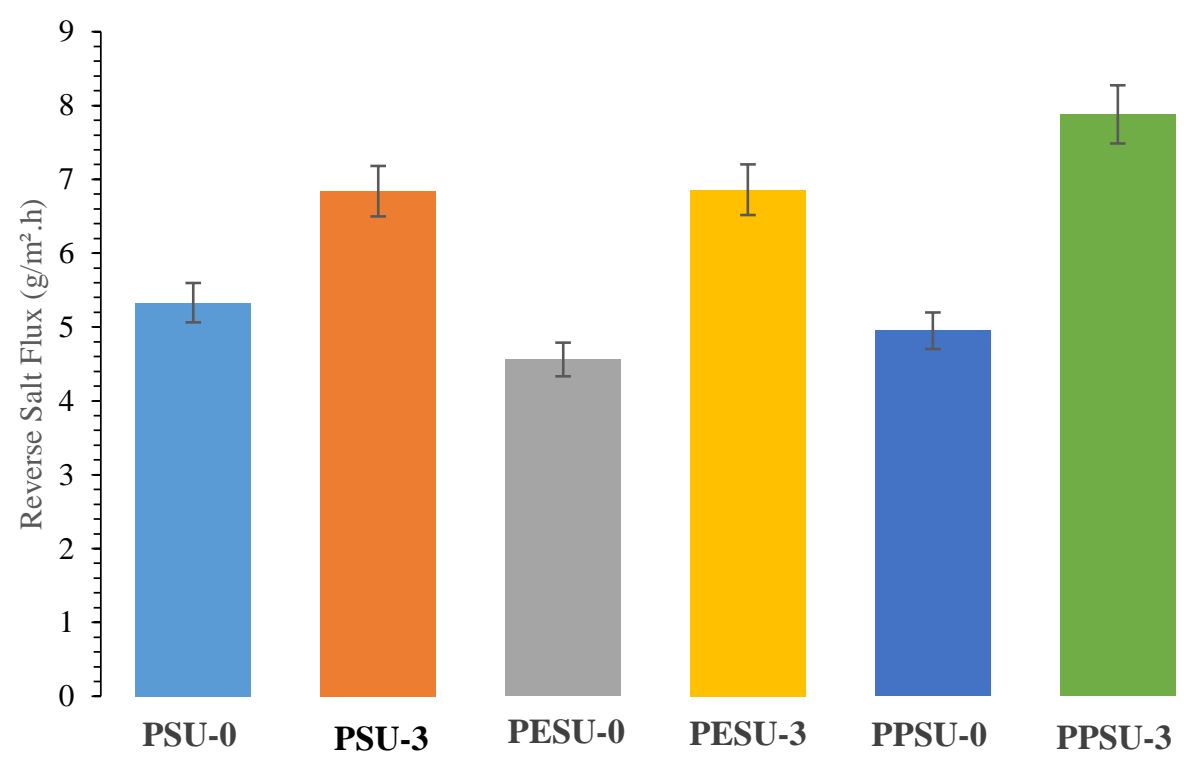

b.

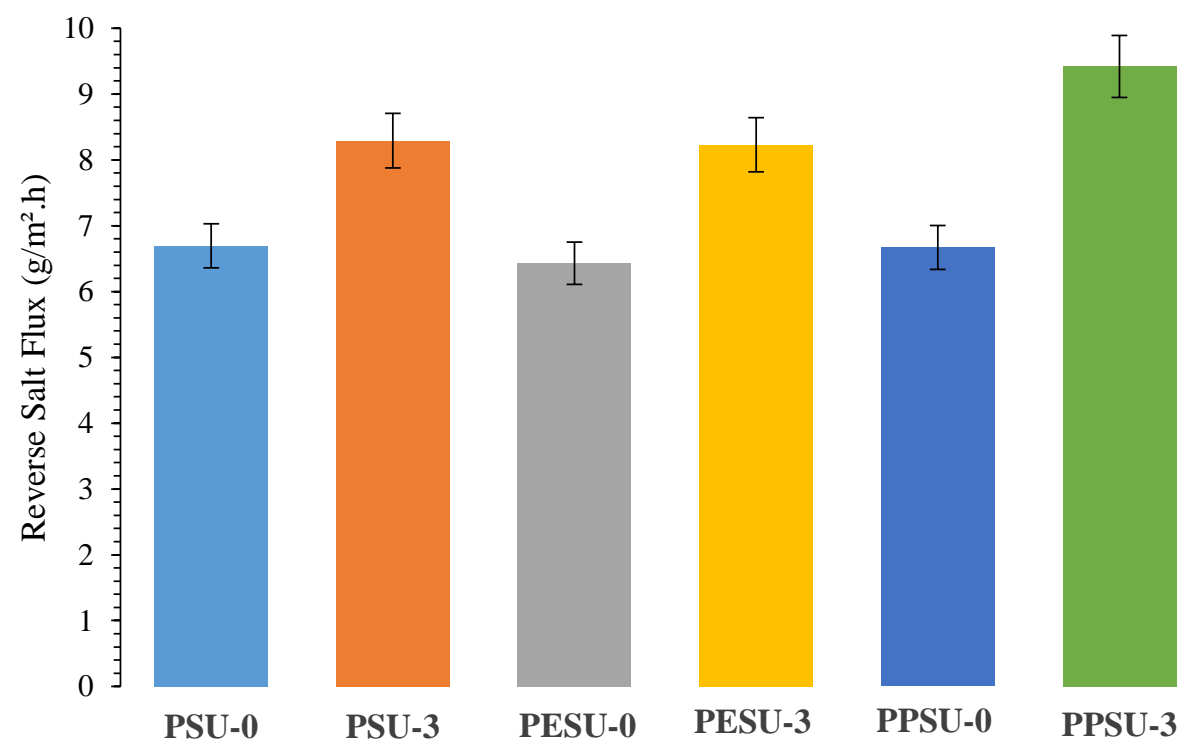

Fig. 8 Reverse salt flux of the synthesized membranes. Testing conditions: DI water as the feed solution, $0.6 \mathrm{M} \mathrm{NaCl}$ as the draw solution, membrane orientations: a) AL-FS, b) ALDS 


\section{Conclusion}

In this study, It has been found that the addition of LiCl to the PSU, PPSU, and PESU casting solutions significantly improved the dope solution properties and morphologies of the asymmetric FO membranes prepared in this study. The water permeability of the membranes increased with the addition of $\mathrm{LiCl}$ by $20.85,21.57$ and $21.95 \%$ for PSU, PESU and PPSU respectively compared with the ones without $\mathrm{LiCl}$. During FO process, water fluxes of the membranes with $\mathrm{LiCl}$ were higher than the original membranes without $\mathrm{LiCl}$. Under AL-FS orientation, water flux increased from 3.59 to $6.71,2.85$ to 6.88 and 3.04 to $5.72 \mathrm{~L} / \mathrm{m}^{2} \mathrm{~h}$ for PSU, PESU and PPSU respectively. While under AL-DS orientation, it increased from 5.09 to $7.29,3.77$ to 10.67 and from 4.13 to $8.48\left(\mathrm{~L} / \mathrm{m}^{2} \mathrm{~h}\right.$ for PSU, PESU and PPSU respectively. The reverse salt flux and specific reverse salt flux of the membranes were investigated. The membranes with $\mathrm{LiCl}$ showed a higher reverse salt flux than those without $\mathrm{LiCl}$. Moreover, the specific reverse salt flux of the membranes increased with the addition of $\mathrm{LiCl}$. The membranes need further improvement to increase water flux and decrease reverse salt flux. For example, using different lithium chloride concertation in the casting solution.

\section{Nomenclature}

$$
\begin{aligned}
& \mathrm{J}_{\mathrm{v}}=\text { Water flux }\left(\mathrm{L} / \mathrm{m}^{2} \mathrm{~h}\right) \\
& m_{d r y}=\text { dry mass of the membranes } \\
& m_{w e t}=\text { wet mass of the membranes } \\
& \rho_{p}=\text { polymer density } \\
& \rho_{w}=\text { water density } \\
& \mathrm{A}=\text { water permeability }(\mathrm{L} / \mathrm{m} 2 . \mathrm{h} \cdot \mathrm{bar}) \\
& \mathrm{A}_{\mathrm{m}}=\text { FO membrane effective surface area }\left(\mathrm{m}^{2}\right) \\
& \mathrm{C}_{0}=\text { feed initial concentration }(\mathrm{g} / \mathrm{L})
\end{aligned}
$$


$\mathrm{C}_{\mathrm{t}}=$ concentration at time $\mathrm{t}(\mathrm{g} / \mathrm{L})$

$\mathrm{Js}=$ reverse salt flux $\left(\mathrm{g} / \mathrm{m}^{2} \mathrm{~h}\right)$

$\mathrm{S}=$ membrane structural parameter $(\mathrm{m})$

$\mathrm{V}_{0}=$ initial feed solution volume $(\mathrm{L})$

$\mathrm{V}_{\mathrm{t}}=$ feed solution volume at time $\mathrm{t}(\mathrm{L})$

$\Delta \mathrm{V}_{\text {feed }}=$ the change in the feed solution volume (L) over a fixed time $\Delta \mathrm{t}(\mathrm{h})$

$\varepsilon=$ porosity of the membranes

\section{References}

[1] J.Y. Lawa, A.W. Mohammada, Assessing the forward osmosis performances using CTA membrane: Effect of solution volume ratio and type of draw solute, Jurnal Teknologi, 79 (2017) 47-52.

[2] J.E.G. T.P.N. Nguyen, H.G. Park and Y.N. Kwon, Development of desirable CTA/CA-based membrane for forward osmosis, in: IWA Busan 2012 World Water Congress \& Exhibition, Busan, Korea, 2012.

[3] W. Ding, Y. Li, M. Bao, J. Zhang, C. Zhang, J. Lu, Highly permeable and stable forward osmosis (FO) membrane based on the incorporation of $\mathrm{Al} 2 \mathrm{O} 3$ nanoparticles into both substrate and polyamide active layer, RSC Advances, 7 (2017) 40311-40320. [4] Y. Chun, D. Mulcahy, L. Zou, I.S. Kim, A short review of membrane fouling in forward osmosis processes, Membranes, 7 (2017) 30.

[5] C. Liu, W. Fang, S. Chou, L. Shi, A.G. Fane, R. Wang, Fabrication of layer-by-layer assembled FO hollow fiber membranes and their performances using low concentration draw solutions, Desalination, 308 (2013) 147-153.

[6] K.Y. Wang, R.C. Ong, T.-S. Chung, Double-skinned forward osmosis membranes for reducing internal concentration polarization within the porous sublayer, Industrial \& Engineering Chemistry Research, 49 (2010) 4824-4831.

[7] L. Setiawan, R. Wang, K. Li, A.G. Fane, Fabrication and characterization of forward osmosis hollow fiber membranes with antifouling NF-like selective layer, Journal of Membrane Science, 394-395 (2012) 80-88. 
[8] Y. Wang, R. Ou, Q. Ge, H. Wang, T. Xu, Preparation of polyethersulfone/carbon nanotube substrate for high-performance forward osmosis membrane, Desalination, 330 (2013) 70-78.

[9] A. Khan, T.A. Sherazi, Y. Khan, S. Li, S.A.R. Naqvi, Z. Cui, Fabrication and characterization of polysulfone/modified nanocarbon black composite antifouling ultrafiltration membranes, Journal of Membrane Science, 554 (2018) 71-82.

[10] S. Darvishmanesh, J.C. Jansen, F. Tasselli, E. Tocci, P. Luis, J. Degrève, E. Drioli, B. Van der Bruggen, Novel polyphenylsulfone membrane for potential use in solvent nanofiltration, Journal of Membrane Science, 379 (2011) 60-68.

[11] Z. Liu, Y. Bai, D. Sun, C. Xiao, Y. Zhang, Preparation and performance of sulfonated polysulfone flat ultrafiltration membranes, Polymer Engineering \& Science, 55 (2015) 1003-1011.

[12] B. Jiang, N. Zhang, B. Wang, N. Yang, Z. Huang, H. Yang, Z. Shu, Deep eutectic solvent as novel additive for PES membrane with improved performance, Separation and Purification Technology, 194 (2018) 239-248.

[13] X. Li, C.H. Loh, R. Wang, W. Widjajanti, J. Torres, Fabrication of a robust highperformance FO membrane by optimizing substrate structure and incorporating aquaporin into selective layer, Journal of Membrane Science, 525 (2017) 257-268. [14] J. Lee, B. Park, J. Kim, S.B. Park, Effect of PVP, lithium chloride, and glycerol additives on PVDF dual-layer hollow fiber membranes fabricated using simultaneous spinning of TIPS and NIPS, Macromolecular Research, 23 (2015) 291-299.

[15] A. Mansourizadeh, A.F. Ismail, Effect of $\mathrm{LiCl}$ concentration in the polymer dope on the structure and performance of hydrophobic PVDF hollow fiber membranes for $\mathrm{CO} 2$ absorption, Chemical Engineering Journal, 165 (2010) 980-988.

[16] L. Shi, R. Wang, Y. Cao, D.T. Liang, J.H. Tay, Effect of additives on the fabrication of poly(vinylidene fluoride-co-hexafluropropylene) (PVDF-HFP) asymmetric microporous hollow fiber membranes, Journal of Membrane Science, 315 (2008) 195204.

[17] M. Tian, Y.-N. Wang, R. Wang, Synthesis and characterization of novel highperformance thin film nanocomposite (TFN) FO membranes with nanofibrous substrate reinforced by functionalized carbon nanotubes, Desalination, 370 (2015) 79-86.

[18] D. Emadzadeh, W.J. Lau, T. Matsuura, A.F. Ismail, M. Rahbari-Sisakht, Synthesis and characterization of thin film nanocomposite forward osmosis membrane with hydrophilic nanocomposite support to reduce internal concentration polarization, Journal of Membrane Science, 449 (2014) 74-85.

[19] X.-Y. Chi, P.-Y. Zhang, X.-J. Guo, Z.-L. Xu, A novel TFC forward osmosis (FO) membrane supported by polyimide (PI) microporous nanofiber membrane, Applied Surface Science, 427 (2018) 1-9. [20] N. Singh, I. Petrinic, C. Hélix-Nielsen, S. Basu, M. Balakrishnan, Concentrating molasses distillery wastewater using biomimetic forward osmosis (FO) membranes, Water research, 130 (2018) 271-280.

[21] M. Amini, M. Jahanshahi, A. Rahimpour, Synthesis of novel thin film nanocomposite (TFN) forward osmosis membranes using functionalized multi-walled carbon nanotubes, Journal of membrane science, 435 (2013) 233-241. 
[22] Z. Dabaghian, A. Rahimpour, Carboxylated carbon nanofibers as hydrophilic porous material to modification of cellulosic membranes for forward osmosis desalination, Chemical Engineering Research and Design, 104 (2015) 647-657.

[23] J. Wei, C. Qiu, C.Y. Tang, R. Wang, A.G. Fane, Synthesis and characterization of flat-sheet thin film composite forward osmosis membranes, Journal of Membrane Science, 372 (2011) 292-302.

[24] T. Sirinupong, W. Youravong, D. Tirawat, W.J. Lau, G.S. Lai, A.F. Ismail, Synthesis and characterization of thin film composite membranes made of PSF-TiO2/GO nanocomposite substrate for forward osmosis applications, Arabian Journal of Chemistry, 11 (2018) 1144-1153.

[25] D. Emadzadeh, W.J. Lau, A.F. Ismail, Synthesis of thin film nanocomposite forward osmosis membrane with enhancement in water flux without sacrificing salt rejection, Desalination, 330 (2013) 90-99.

[26] G. Arthanareeswaran, D. Mohan, M. Raajenthiren, Preparation, characterization and performance studies of ultrafiltration membranes with polymeric additive, Journal of Membrane Science, 350 (2010) 130-138.

[27] S. Liyanaarachchi, S. Muthukumaran, J. Kaiser, P. Rogers, L. Shu, H.K. Shon, V. Jegatheesan, Computing the effective diffusion coefficient of solutes in a multi-salts solutions during forward osmosis (FO) membrane filtration: Experiments and mathematical modelling, Journal of environmental management, 214 (2018) 215-223. [28] P. Xiao, J. Li, Y. Ren, X. Wang, A comprehensive study of factors affecting fouling behavior in forward osmosis, Colloids and Surfaces A: Physicochemical and Engineering Aspects, 499 (2016) 163-172.

[29] L. Jin, Z. Wang, S. Zheng, B. Mi, Polyamide-crosslinked graphene oxide membrane for forward osmosis, Journal of Membrane Science, 545 (2018) 11-18.

[30] H. Cui, H. Zhang, W. Jiang, F. Yang, Preparation and assessment of carboxylate polyelectrolyte as draw solute for forward osmosis, Environmental Science and Pollution Research, 25 (2018) 5752-5761.

[31] B. Mi, M. Elimelech, Chemical and physical aspects of organic fouling of forward osmosis membranes, Journal of Membrane Science, 320 (2008) 292-302.

[32] P.G. Nicoll, Forward Osmosis-Abrief Introduction, in: Proceedings of the The International Desalination Association World Congress on Desalination and Water Reuse, Tianjin, China, 2013.

[33] S. Wu, S. Zou, Y. Yang, G. Qian, Z. He, Enhancing the performance of an osmotic microbial fuel cell through self-buffering with reverse-fluxed sodium bicarbonate, Chemical Engineering Journal, 349 (2018) 241-248.

[34] M. Yu, H. Zhang, F. Yang, A study of a ferric-lactate complex as draw solute in forward osmosis, Chemical Engineering Journal, 314 (2017) 132-138.

[35] H.T. Nguyen, N.C. Nguyen, S.-S. Chen, H.H. Ngo, W. Guo, C.-W. Li, A new class of draw solutions for minimizing reverse salt flux to improve forward osmosis desalination, Science of the Total Environment, 538 (2015) 129-136.

[36] R.W. Holloway, R. Maltos, J. Vanneste, T.Y. Cath, Mixed draw solutions for improved forward osmosis performance, Journal of Membrane Science, 491 (2015) 121 131. 
[37] S. Morales-Torres, C.M.P. Esteves, J.L. Figueiredo, A.M.T. Silva, Thin-film composite forward osmosis membranes based on polysulfone supports blended with nanostructured carbon materials, Journal of Membrane Science, 520 (2016) 326-336. [38] S. Zou, Y. Gu, D. Xiao, C.Y. Tang, The role of physical and chemical parameters on forward osmosis membrane fouling during algae separation, Journal of Membrane Science, 366 (2011) 356-362. 